\title{
ENTRE PATAGONES Y CABALLEROS ANDANTES. A MODO DE INTRODUCCIÓN
}

\author{
Diego Téllez Alarcia \\ Universidad de La Rioja
}

\begin{abstract}
"Un día, de pronto, descubrimos a un hombre de gigantesca estatura, el cual, desnudo sobre la ribera del puerto, bailaba, cantaba y vertía polvo sobre su cabeza (...) Era tan alto él, que no le pasábamos de la cintura"1. Quien suscribe estas palabras es Antonio Pigafetta, un caballero de Rodas natural de Vicenza, que acompañaba a Magallanes en la primera vuelta al mundo. Pigafetta había recalado en España como tantos otros aventureros de la época -comienzos del s. XVI- con la intención de hacer fortuna al servicio del Emperador. A su llegada al puerto de Barcelona habían llegado a sus oídos noticias de la futura expedición magallánica a descubrir las Islas de las Especias, por lo que, "cargado de cartas de recomendación", como él mismo admite, había viajado a Sevilla donde se aprestaban las naves. El comandante portugués había prestado atención a las recomendaciones y lo había puesto a su servicio.

Pero lo que más nos interesa de la historia de Pigafetta tiene que ver más con su afición a la pluma que con sus ambiciones personales. Gracias a él conservamos un diario bastante detallado de toda la primera circunnavegación del globo terráqueo, liderada por el insigne marino portugués, y completada por Juan Sebastián Elcano. Este episodio de la obra de Pigafetta puede servirnos perfectamente de prólogo a nuestro compendio de estudios dedicados al mundo de la frontera en el Imperio Hispánico durante el s. XVIII. Porque es en las narraciones de Pigafetta donde se forja uno de los mitos más persistentes de esa galaxia físico-simbólica: el mito de los "Patagones" 2 .
\end{abstract}

1. Pigafetta, A., Relación del primer viaje alrededor del mundo. Madrid, 1985, (1526), p. 64.

2. Casamiquela, R. M. (et. al.), Del mito a la realidad. Evolución iconográfica del pueblo tehuelche meridional. Buenos Aires, 1982. 
Y es que el ejemplo de Pigafetta y los "Patagones" es, desde luego, uno de los más interesantes para estudiar el influjo que el imaginario caballeresco tuvo en el Nuevo Mundo durante la época de la conquista. Muchas de las mesnadas descubridoras vieron las nuevas tierras descubiertas con los ojos de las novelas de caballería, que tan duramente criticaría un siglo después Cervantes en su Quijote. Es la teoría de Ida Rodriguez Prampolini y su Amadises de América3. Hay, desde luego, más ejemplos de retroalimentación entre la novela de caballería y la crónica, como los hallados por Leonard con los tempranos relatos colombinos sobre las amazonas. O la célebre "Ciudad de los Césares", una urbe en la que "el oro y la plata, las gemas y las perlas abundaban tanto que aquellos eran utilizados para construir vasijas, cubiertos e instrumentos varios, de uso casero y aún de labranza". Según el mito esta ciudad era de población mestiza: "hombres blancos que habíanse casado con indias" se aseguraba que había sido fundada por los supervivientes de los desastres australes: los de los naufragios de las naves de Simón de Alcazaba o de la flota del obispo de Plasencia, los compañeros perdidos de Alonso Camargo, los fugitivos de las dos ciudades efímeras que había fundado en el estrecho de Magallanes Sarmiento Gamboa: "de estos restos misérrimos surgiría la idea de la ciudad que era portento de riqueza, del clamor de los moribundos nació la urbe en que el hombre alcanzaba la divina condición de inmortalidad" ${ }^{\prime 4}$. Luego estaba, por supuesto, el archiconocido mito del Dorado.

En el caso de los gigantes y los patagones, Pigafetta emplea imágenes de una obra de caballería más bien temprana: el Libro segundo de Palmerín. Publicada en Sevilla siete años antes de la partida de Magallanes (por lo tanto en 1512) trata de "los grandes fechos de Primaleón" (cap. CXXXIII, p 142). En sus páginas aparecerá un monstruo Ilamado "Patagón", "muy inteligente y gran amante de mujeres", ser con figura de perro, grandes orejas, dientes descomunales y pies de ciervo. El empleo que hará Pigafetta en su crónica del apelativo es, obviamente, una alusión literaria y no directa. Hay quien va más allá y defienden que la figura literaria del gigante Patagón sería una recreación de otro personaje, aparecido esta vez en el archiconocido Amadís con el nombre del gigante Ardán Canileo, personaje inspirador que posee características muy similares al monstruoso Patagón.

Pues bien, todavía en el s. XVIII, el mito del gigantismo de los "patagones" está de rabiosa actualidad. Para comenzar, muchos de los cronistas españoles de Indias lo han citado en sus páginas a lo largo de los siglos XVI y XVII. Fernández de Oviedo en su Historia General y Natural de las Indias, indica que "la costa a ambos lados del Estrecho de Magallanes está habitada por unos gigantes a los cuales Ilamaron patagones por sus grandes pies, que tienen una esta-

3. Rodriguez Prampolini, I., Amadises de América. La hazaña de Indias como empresa cabaIleresca. México, 1948.

4. Hilarion Lenzi, J., Historia de Santa Cruz. Buenos Aires, 1970. 


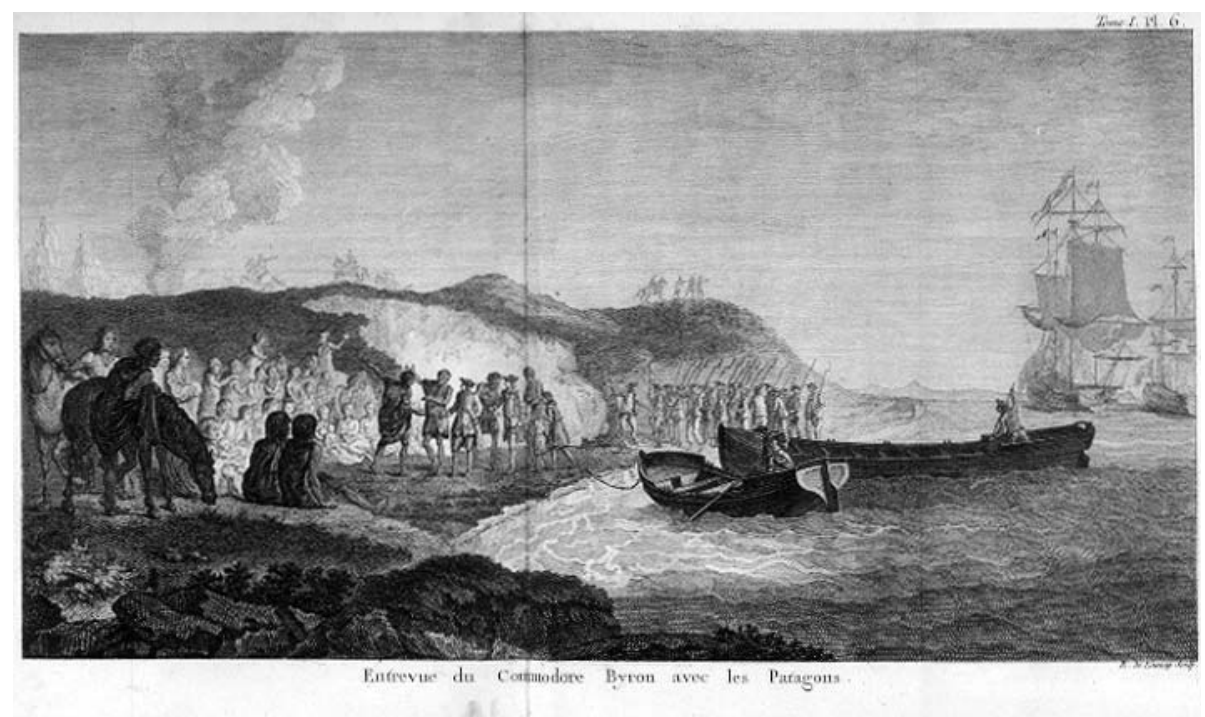

Imagen 1. Entrevista del comodoro Byron con los patagones, lámina del libro de Hawkesworth.

tura de trece palmos, grandísima fuerza y son tan veloces en el correr como ligeros caballos o más". Cieza de León, Gomara y Gutiérrez de Santa Clara todavía han extendido aún más el ámbito geográfico de expansión de los gigantes. El segundo, por ejemplo, en su Historia de las Indias, afirma que hubo gigantes en el Perú porque se hallaron en aquellos parajes "huesos y calaveras con dientes de tres dedos en gordo y cuatro en largo", huesos que probablemente pertenecían a animales del Terciario.

Por si esto fuera poco, en pleno siglo de las Luces los autores abundan en la leyenda. En España, en 1754, José Torrubia defiende todavía tesis gigantológicas en su Aparato para la Historia Natural Española

Por esas mismas fechas, en 1756, Charles de Brosses hace lo propio en Francia con su Histoire des navigations aux Terres Australes ${ }^{6}$. Ni siquiera los viajes de Bougainville modificarán el panorama. El capellán de este célebre navegante francés, Dom. Pernetty, ilustrará su relación de las navegaciones de su jefe con patagones desproporcionados ${ }^{7}$.

5. Torrubia, J., Aparato para la Historia Natural Española. Madrid, 1754.

6. Brosses, C. de, Histoire des navigations aux Terres Australes: contenant ce que I'on sçait des moeurs \& des productions des contrées découvertes jusqu'à ce jour. París, 1756.

7. Pernetty, D., Histoire d'un voyage aux Isles Malouines, fait en 1763 \& 1764; avec des observations sur le Detroit de Magellan, et sur les patagons. París, 1770. 


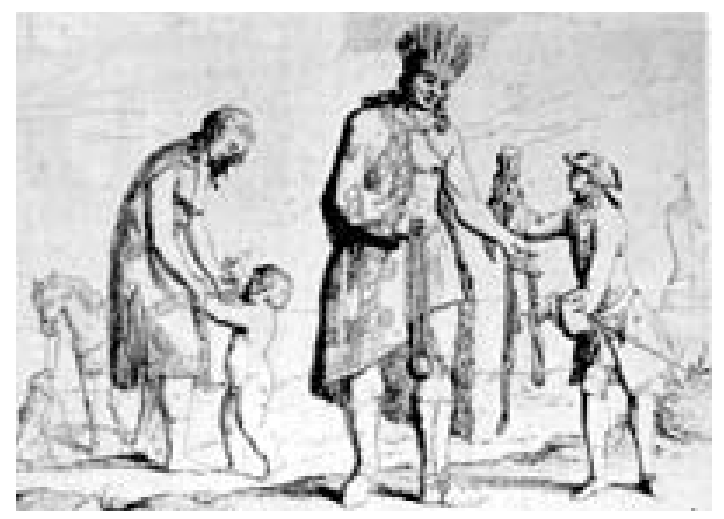

Imagen 2. Ilustración de la obra de Dom. Pernetty.

Tampoco los ingleses se libran del yerro. Hawkesworth incluye en su Diario del viaje alrededor del mundo, gráficos en los que se comparaba la estatura de los patagones con la de los europeos, siendo el resultado grotesco: las rodillas de aquellos llegan a la altura de éstos, acabando por duplicar su estatura ${ }^{8}$. Eso llevaría a estos indios a medir más de tres metros.

Todavía a la altura de 1801 Carlos Amoretti, en su traducción al francés de la obra de Pigaffeta "lejos de tratar con cordura las exageraciones de aquel (Pigafetta), procura testimonios que en las mismas abunden" ${ }^{\prime 9}$. Por las páginas de su prólogo desfilan los testimonios pro gigantológicos de navegantes como Byron, Wallis, Cook, Forster, y los más circunspectos de Winter, Nargourough o Bounganville. Amoretti se apoya en los primeros, aduciendo que "los habitantes de las costas más meridionales de América no son todos de gigantesca estatura, sino únicamente los individuos de algunas tribus tienen esa talla". En su opinión "como no habitan siempre en el mismo sitio, ha sucedido que algunos navegantes no los vieron"10.

No es raro que Amoretti no conociese los datos aportados por la gran expedición científica de la Ilustración española: la de Malaspina. Sus resultados apenas fueron divulgados. No se hizo publicación alguna ya que Malaspina se vio envuelto en la conjura que lleva su nombre, fue encarcelado y, por tanto, desacreditado. Pero lo cierto es que el navegante italiano había permanecido en Puerto Deseado, un puerto natural situado en los $48^{\circ}$ de latitud Sur, entre el 2 y el 13 de diciembre de 1789, donde había contactado con un importante grupo

8. Hawkesworth, An Account of the Voyages undertaken... for making Discoveries in the Southern Hemisphere. Londres, 1773.

9. Sarmiento de Gamboa, P., Viajes al Estrecho de Magallanes. Madrid, 2000, p. 14.

10. Amoretti, C., Premier voyage autour du Monde, par le Chur Pigafetta. París, 1801. 


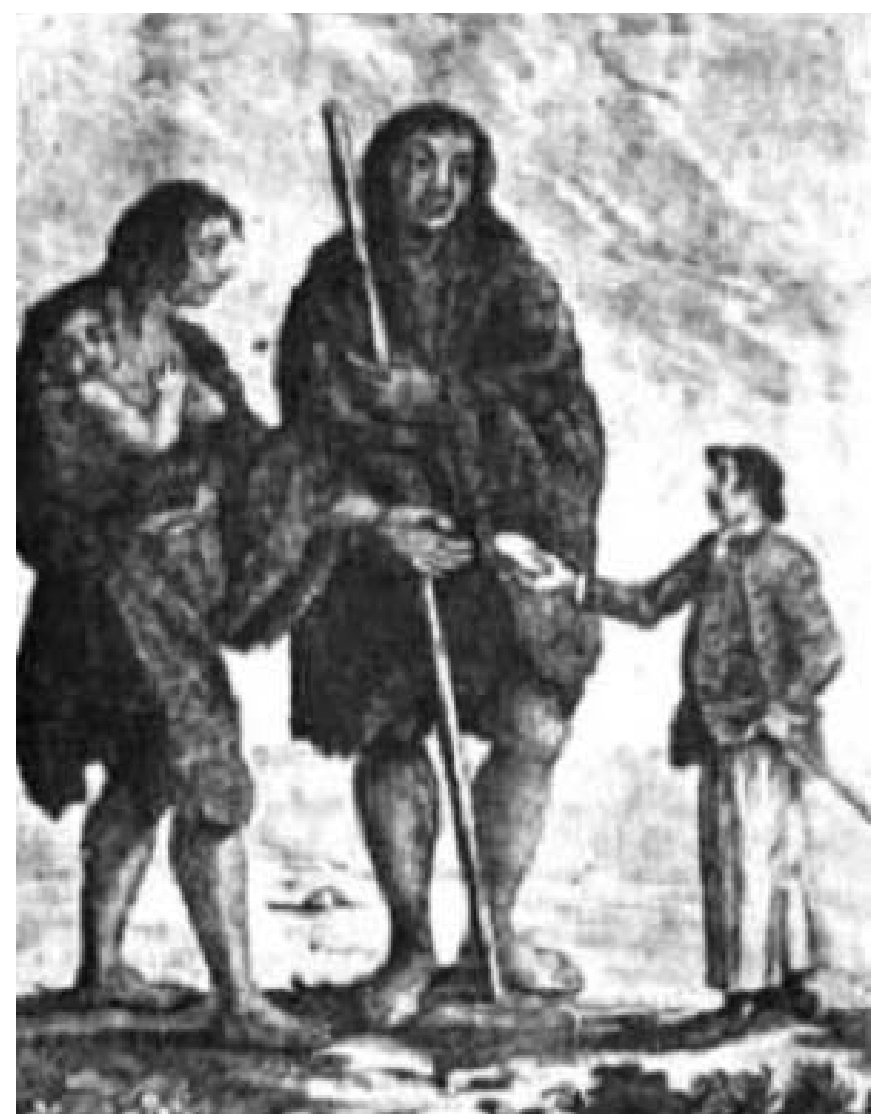

Imagen 3. Ilustración de la obra de Hawkesworth.

de "patagones": "Abbiamo avuto la fortuna di trovare in queste vicinanze i celebri Patagoni. Erano questi in numero di 60 famiglie (...) Il più grande di loro era di 6 piedi e sete pulgade e gli altri, quantunque un poco più piccoli, avevano le trazze d'omini giganteschi"11.

Las sensacionalistas expresiones de Ala Ponzone contrastarían con los resultados de las mediciones realizadas por Pineda, que descartarían definitivamente el "gigantismo" de los patagones ${ }^{12}$. En sus láminas José del Pozo representaría de un

11. Fabio Ala Ponzone a su padre, 11 de diciembre de 1789, Manfredi, D., Alessandro Malaspina e Fabio Ala Ponzone. Lettere dal Vecchio e Nuovo Mondo (1788-1803). Bolonia, 1999, pp. 209-210.

12. Museo de Ciencias Naturales, Madrid, Pineda, 1789-90, Mss. Leg. 1, carp. 8. y Mss. Leg. 100, f. 155-161. 


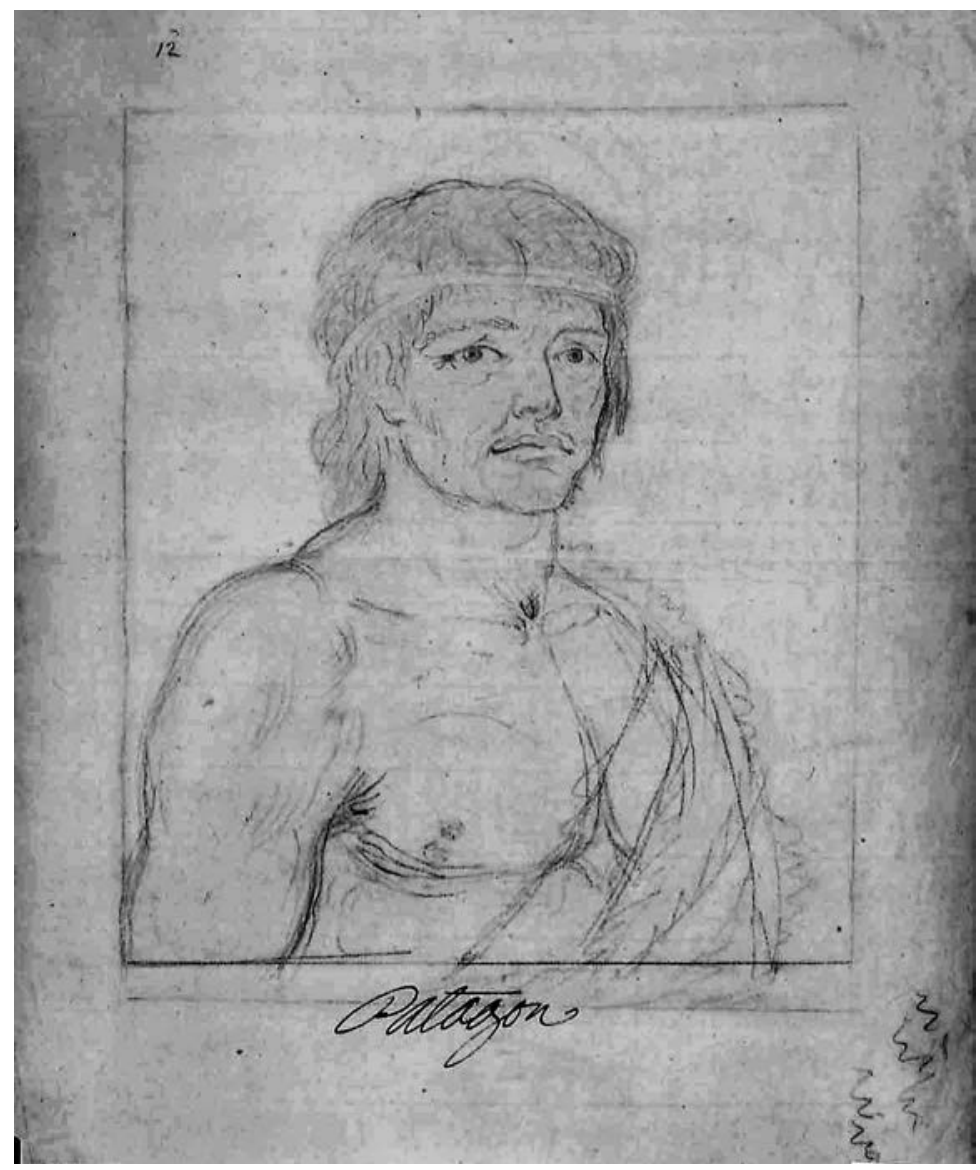

Imagen 4. Del Pozo, Patagón. Colección Malaspina, Museo Naval de Madrid, MS 1725 (9).

modo mucho más realista a estos nativos ${ }^{13}$. Malaspina incluso llegaría a enviar a España huesos presuntamente humanos de gran tamaño para que fuesen estudiados por la Real Academia de la Historia. Clavijo, Ramón Sarais y Agustín Ginesta zanjarían la cuestión dictaminando su procedencia no humana ${ }^{14}$.

13. Pueden consultarse en Palau, M., Catálogo de los dibujos de la Expedición Malaspina. Madrid, 1980 y en Higueras Rodríguez, M. D., Catálogo crítico de los documentos de la Expedición Malaspina (1789-1794) del Museo Naval. Madrid, 1985.

14. Gandía, E. de, Historia crítica de los mitos de la conquista americana. Madrid, 1929, pp. 37-38. Ver también Pedro, A. E. de, “¿Salvajes o civilizados? La imagen del indio americano en la Expedición Malaspina". Historia 16226 (1995), pp. 29-34. 


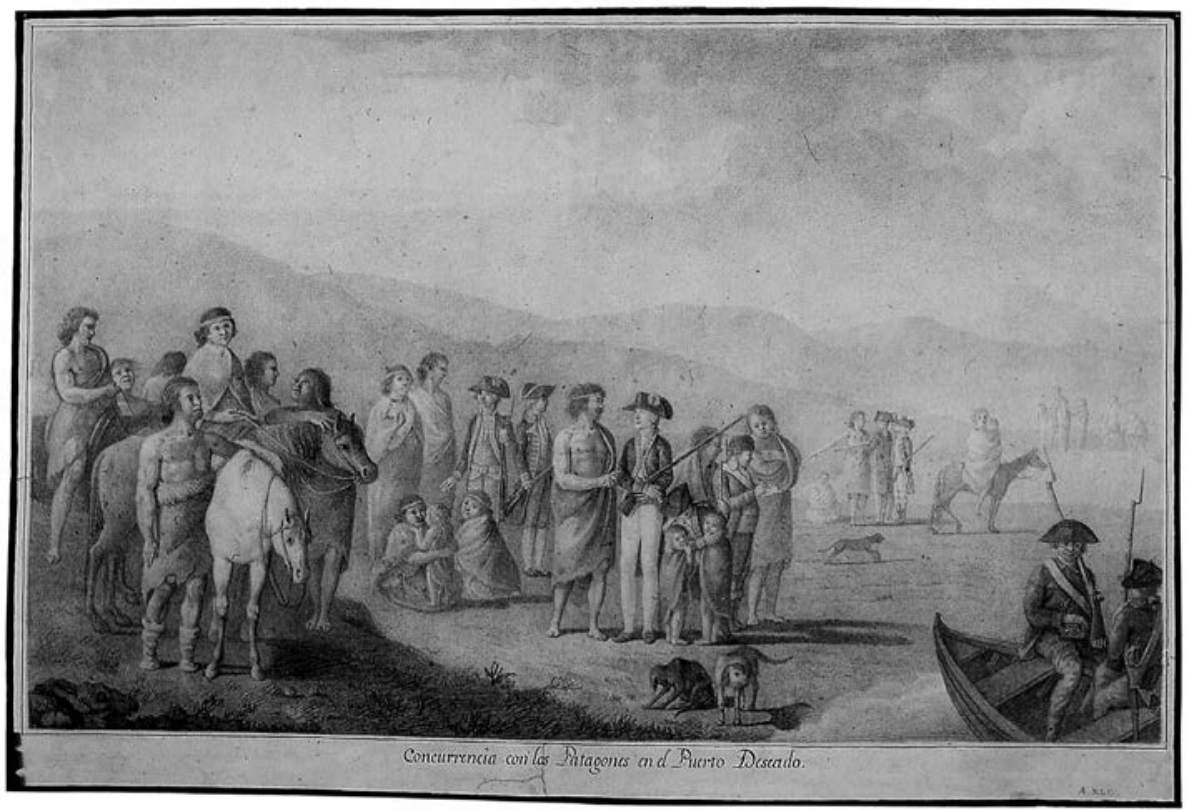

Imagen 5. Concurrencia con los patagones en el Puerto Deseado, Colección Malaspina, Museo Naval de Madrid, MS 1726 (70).

El ejemplo de la pervivencia del mito de los Patagones nos da una idea de hasta qué punto la frontera seguía siendo, en el "largo" siglo XVIII, un espacio plagado de representaciones desviadas, prejuicios y mitología.

No nos cuenta, sin embargo, otras cuestiones importantes a las que atenderemos a lo largo de este número monográfico: las relaciones entre nativos y colonos, los procesos de integración y asimilación en ambos campos, la fluidez de las relaciones económicas y sociales, incluso políticas, etc. El objetivo final no es sino ofrecer un panorama geográficamente amplio (desde la Patagonia a las Filipinas, pasando por Nueva España, Nueva Granada, Perú, Uruguay o Chile) que nos permita aportar nuestro granito de arena a los estudios de la "frontera", línea de investigación que tan fructíferos resultados ha dado en los últimos años a la historiografía española y americanista y que tan prometedora sigue siendo para investigadores de la más diversa procedencia académica ${ }^{15}$.

15. El origen de este monográfico fue el mesa redonda "Relationships between natives and settlers in Spanish America" coordinada por el profesor Diego Téllez Alarcia durante el duodécimo congreso cuatrienal de la International Society for Eighteenth Century Studies, que tuvo lugar en Montpellier en agosto de 2007. 
